\title{
Effect of Insulation Layer Composite and Water Adsorption on Bonding Performance in Heat Barriers
}

\author{
Mahmoud Emad Awad* (D), Mohamed Nasser
}

Department of Chemical Engineering, Cairo University, Cairo, Egypt

\section{A R T I C L E I N F O}

Received: 21 August 2019

Revised: 19 October 2019

Accepted: 23 October 2019

Available online: 26 October 2019

\section{K E Y W O R D S}

Solid rocket motor HTPB propellant Insulation layer Bonding property

\section{A B S T R A C T}

Thermal insulation layer in solid rocket motors is a vital component during the rocket flight. Many factors can affect the performance of this insulation layer. Bonding property between rocket propellant and the thermal insulation layer are examined in this study. Hydroxyl terminated polybutadiene (HTPB) and isophorone diisocyanate (IPDI) as a curative was chosen as the most common type of rocket propellant. The effect of two types of polymeric insulation layer such as nitrile butadiene rubber (NBR) and ethylene-propylene-diene monomer (EPDM), on the bonding performance at the interface between (HTPB/IPDI) propellant and the respective insulation layer has been investigated. Results revealed that both types of insulation layer considerably decreased the interfacial bonding performance of the (HTPB/IPDI) propellant. NBR was proven to be more severe on weakening the adhesion strength than that of the EPDM. We further investigated the effects of the thickness and water content of NBR on the bonding performance, and proved that bonding strength was inversely proportional to the thickness and the water content.

\section{G RA P H I C A L A B S T RACT}
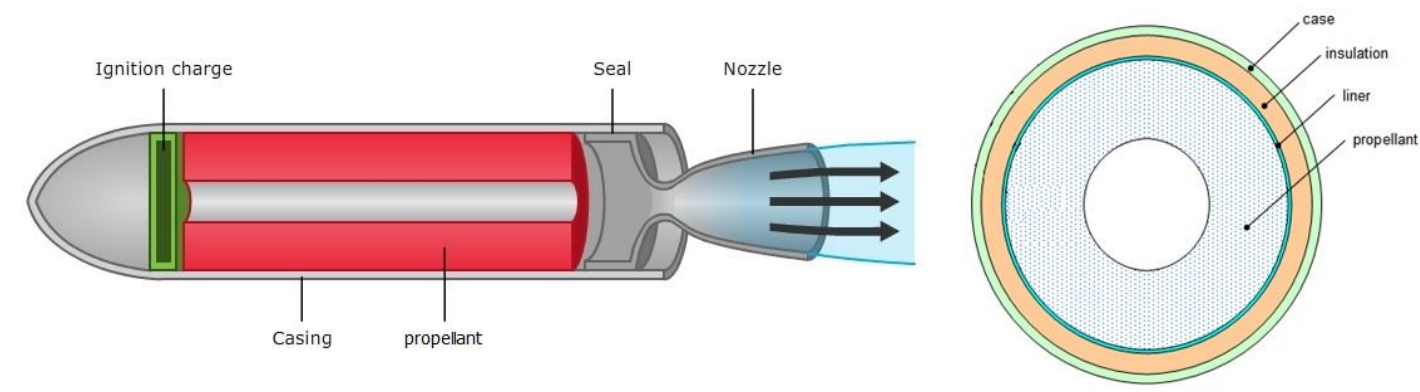

* Corresponding author's E-mail address: ma7mood.3emad@gmail.com 


\section{Introduction}

Rocket motor mainly consists of shell, thermal insulating layer, liner and propellant as shown in Figure 1. Liner is a kind of special adhesive, bonding the thermal insulation layer, shell, and the propellant. The main function of the liner is to prevent the unexpected increase of burning surface of the propellant when the motor is working [1]. The manufacturing process of the combustion chamber consists of the following steps: first mold the insulating layer into shape, second spray or brush the liner slurry on the insulation layer, third cast propellant slurry when the liner is curing to a certain extent or semi-curing state.

The function of the liner and the manufacturing process of combustion chamber make the interface of liner between propellant and insulation layer the weakest interface where problems arise [4]. It was found that, many factors affect the interfacial bonding property between liner and propellant [5]. Among those factors, heat insulation layer is the major factor effecting the bonding property [6]. The insulation layer contains active groups, such as hydroxyl groups that can adsorb water molecules and at the same time can absorb isocyanate compounds $[7,8]$. Therefore, the effect of the water in the insulating layer on bonding property has attracted a considerable attention. However, the following factors influencing the bonding interface such as the types, thickness, and water removal conditions of insulation layer, have not been publicly reported in any research study.

\section{Experimental}

\section{Materials}

NBR insulation layer is a kind of rubber filled with precipitated silica and asbestos fiber which is vulcanized by sulfur. EPDM is a kind of rubber filled with precipitated silica and organic fiber, which is vulcanized by peroxide. The vulcanizing condition of the two kinds of insulation specimen is determined as follows: the molding temperature is $160^{\circ} \mathrm{C}$, the molding pressure is $10 \mathrm{MPa}$, and the molding time is 40 min [9]. The solid content of HTPB propellant (the sum of $\mathrm{AP}, \mathrm{Al}$ and $\mathrm{RDX}$ ) is $88 \%$ cured by isophorone diiscyanate (IPDI) [10]. The curing condition is chosen to be at $60{ }^{\circ} \mathrm{C}$ for 8 days. HTPB liner is reinforced by precipitated silica and cured by polyisocyanate. The curing condition is the same as HTPB/IPDI propellant.

\section{Specimen and test}

The dumbbell shaped specimens of the propellant were prepared according to the ASTM D412 C standard [11]. The tensile strength test condition was determined as follows: the test temperature of $25{ }^{\circ} \mathrm{C}$ and the stretching speed of $100 \mathrm{~mm} / \mathrm{min}$. The structure of the rectangular bonding specimen containing insulating layer is shown in Figure 2. The thickness of the insulation was $2 \mathrm{~mm}$. The bonding test condition determined as follows: the test temperature of $25^{\circ} \mathrm{C}$ and the stretching speed of $20 \mathrm{~mm} / \mathrm{min}$.

Figure1. Solid rocket motor scheme and then wait for the propellant solidification molding $[2,3]$
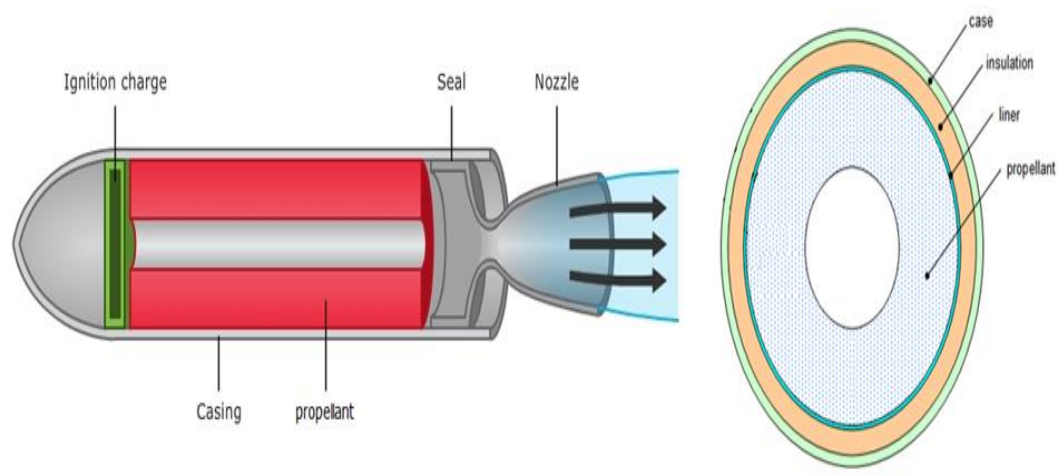
Figure 2. Structure and size of the rectangular bonding specimen

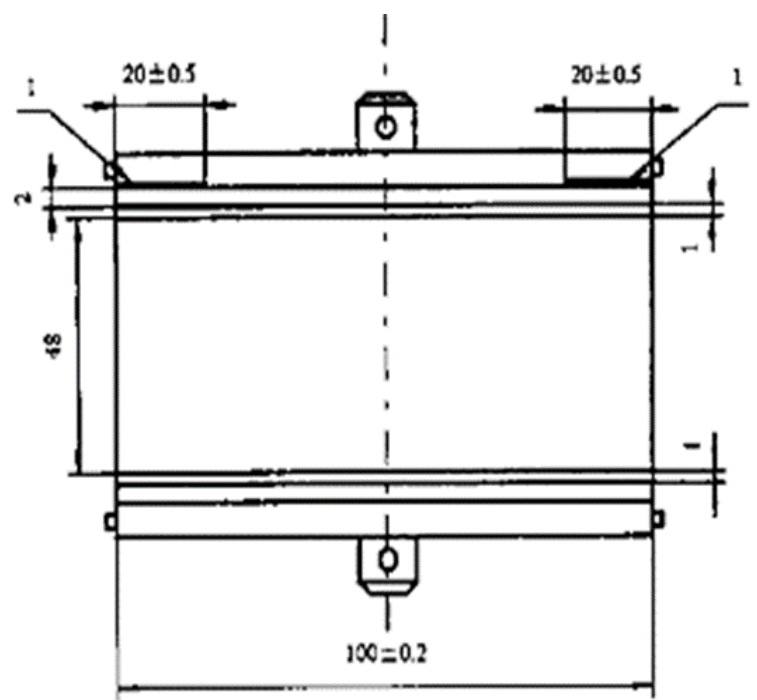

1. Debonding site

2. Propellant

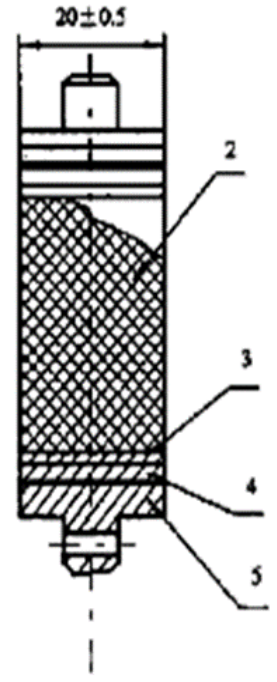

3. Liner

4. Insulation layer $\quad 5$. Steel specimen

Table 1. Effect of insulation layer on bonding property

\begin{tabular}{|c|c|c|c|}
\hline Sample No. & Type of insulation layer & $\sigma_{\text {bond }}(\mathrm{Mpa})$ & Failure mode \\
\hline \multirow{2}{*}{1} & - & 1.27 & \multirow{8}{*}{ Cohesive failure of propellant } \\
\hline & EPDM & 0.97 & \\
\hline \multirow{2}{*}{2} & - & 1.01 & \\
\hline & NBR & 0.85 & \\
\hline \multirow{2}{*}{3} & - & 0.83 & \\
\hline & NBR & 0.67 & \\
\hline \multirow{2}{*}{4} & - & 0.91 & \\
\hline & NBR & 0.72 & \\
\hline
\end{tabular}

The tensile strength for the propellant and the rectangular adhesive specimen was tested using the universal material experiment machine (INSTRON 4301).

\section{Results and Discussion}

\section{Effect of insulation layers on bonding property}

The influence of the insulation layer on the liner/propellant interface bonding property is shown in Table 1. Compared with the specimen without EPDM or NBR insulation layer, the bonding strength of the specimen with insulation layer is obviously lower. The failure mode was cohesive failure of propellant.

Either EPDM or NBR, contains the reinforcing agent of precipitated silica. There is a large amount of hydroxyl on the surface of precipitated silica [12]. The hydroxyl groups of precipitated silica not only can form hydrogen bond with water molecular to cause the insulation layer to have a certain water absorption property, but also can react with the isocyanate, enabling the curing agent at the interface to be additionally consumed. The water absorption of EPDM and NBR both with the thickness equals $2 \mathrm{~mm}$ at different humidity conditions is depicted in Figure 3 and Figure 4, respectively. 
Figure 3. Water absorption of NBR (thickness $=2 \mathrm{~mm}$ ) vs time at different humidity conditions $\left(20^{\circ} \mathrm{C}\right)$

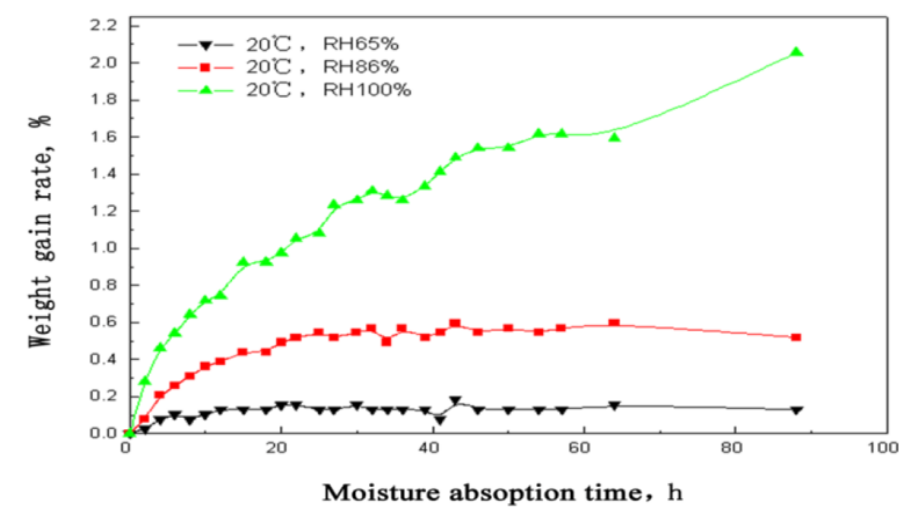

Figure 4. Water absorption of EPDM (thickness $=2 \mathrm{~mm}$ ) vs time at different humidity conditions (20 ${ }^{\circ} \mathrm{C}$ )

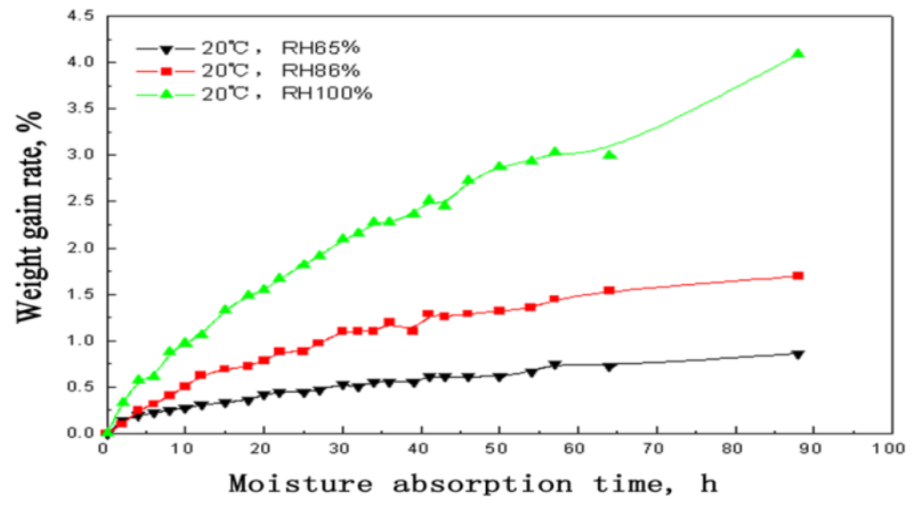

The results indicated that as the humidity enhanced and the moisture absorption time extended, the water absorption of the insulation layer increased. Therefore, it can be concluded that, the -OH group in the insulation layer and the absorbed water may consume the -NCO group at the interface, which results in reducing the ratio of the curing agent of propellant. As a result, the bonding strength of steel/insulation layer/liner/propellant specimen is obviously lower than the steel/liner/propellant specimen.

Effect of insulation layer types on bonding property

Under the uniform conditions (the same propellant, the same liner, the same insulation layer thickness and the same water removal condition), the effect of EDPM and NBR on bonding property is shown in Table 2 . Compared with EPDM, the weakening of bonding property for NBR is more obvious. The reason for the above experimental phenomenon can be summarized as the differences in absorption characteristics of IPDI. To verify the conjecture, the absorption property for IPDI of insulation layer was studied. As shown in Figure 5, the weight gains rates of NBR $(2 \mathrm{~mm})$ immersed in IPDI is obvious higher than EPDM ( $2 \mathrm{~mm}$ ).

The relationship between the weight gain of insulation layer immersed in IPDI and the diffusion coefficient is as follows:

$\frac{\mathrm{m}}{\mathrm{m}_{\mathrm{o}}}=\frac{\mathrm{w}_{\mathrm{i}}+\mathrm{m}_{\mathrm{o}}}{\mathrm{m}_{\mathrm{o}}}=\frac{\mathrm{w}_{\mathrm{i}}}{\mathrm{m}_{\mathrm{o}}}+1=\frac{A \rho}{\mathrm{m}_{\mathrm{o}}}\left[\frac{\mathrm{Dt} \mathrm{t}_{1}}{\pi}\right]^{\frac{1}{2}}+1$

In Eq. 1:

$\mathrm{m}$ : Weight of insulation layer after absorbing IPDI (g)

$\mathrm{m}_{\mathrm{o}}$ : Initial weight of insulation layer, $(\mathrm{g})$

$\mathrm{w}_{1}$ : The weight of IPDI absorbed by the insulation layer, (g)

A: Area of insulation layer, $\left(\mathrm{m}^{2}\right)$

$\rho$ : The density of IPDI, $1.06 \mathrm{E}+3 \mathrm{~kg} \cdot \mathrm{m}^{-3}$

$\mathrm{t}_{1}$ : Absorption time, $(\mathrm{s})$

D: diffusion coefficient, $\left(\mathrm{m}^{2} \cdot \mathrm{s}^{-1}\right)$

According to the formula: $m_{o}=A d_{i} \rho_{i}$ 
Where $\left(\mathrm{d}_{\mathrm{i}}\right.$, the thickness of insulation layer; $\rho_{i}, \quad$ the density of insulation layer).

Table 2. The effect of type of insulation layer on adhesive property

\begin{tabular}{cccc} 
Sample no. & \multicolumn{2}{c}{$\sigma_{\text {bond }}(\mathrm{Mpa})$} & Failure mode \\
4 & EPDM & NBR & \\
5 & 0.94 & 0.81 & Cohesive failure of propellant \\
6 & 1.10 & 1.01 & \\
\hline
\end{tabular}

Figure 5. Weight gain rate of insulation layer $(2 \mathrm{~mm}$ thick) immersed in IPDI (20 ${ }^{\circ} \mathrm{C}$ )

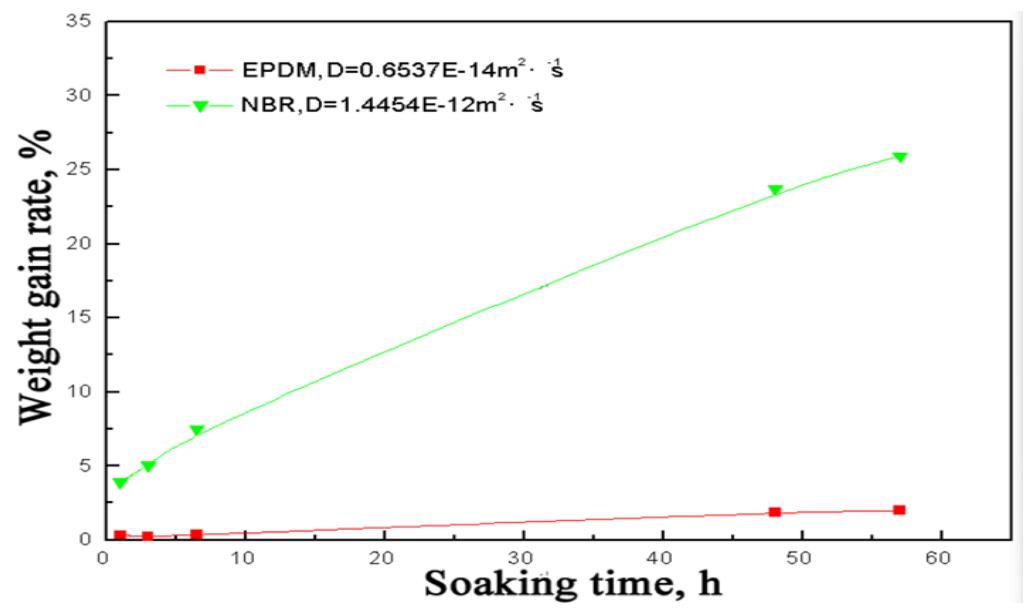

Equation 1 can be transformed into Equation 2:

$\frac{m}{m_{o}}=\frac{\rho A_{i} d_{i}}{m_{o} d_{i}}\left[\frac{D t_{1}}{\pi}\right]^{\frac{1}{2}}+1=\frac{\rho A_{i}}{\rho_{i} d_{i}}\left[\frac{D t_{1}}{\pi}\right]^{\frac{1}{2}}+1$ (Eq. 2)

Plot the weight increasing rate of insulation layer and square root of time, the relationship between slope $(\mathrm{k})$ and diffusion coefficient is as follows:

$K=\frac{d}{d \sqrt{t}}\left\lfloor\frac{m}{m_{o}}\right\rfloor=\frac{\rho}{\rho_{i} d_{i}}\left\lfloor\frac{D}{\pi}\right\rfloor^{\frac{1}{2}}$

The diffusion coefficient can be calculated by formula 4 :

$D=\frac{K^{2} \rho_{i}{ }^{2} d_{i}{ }^{2} \pi}{\rho^{2}}$

In Equation 4:

$\mathrm{k}$ : Slope, $\left(\mathrm{s}^{-1 / 2}\right)$

di: The thickness of insulation layer, (m)

$\rho_{\mathrm{i}}$ : The density of insulation layer
Density of NBR and EPDM was $1.25 \mathrm{E}+3$ $\mathrm{kg} \cdot \mathrm{m}^{-3}$ and $1.05 \mathrm{E}+3 \mathrm{~kg} \cdot \mathrm{m}^{-3}$, respectively [13]. Diffusion coefficient of IPDI in NBR and EPDM was $1.4454 \mathrm{E}-12 \mathrm{~m}^{2} \cdot \mathrm{s}^{-1}$ and $6.537 \mathrm{E}-15 \mathrm{~m}^{2} \cdot \mathrm{s}^{-1}$, respectively. Diffusion coefficient of IPDI in NBR is about 200 times higher than that of the EPDM. It is assumed that the reaction follows the Fick, s second law, the migration of curing agent can be described by formula 5 .

$\frac{\partial c}{\partial t}=\frac{\partial}{\partial x}\left(D \frac{\partial c}{\partial x}\right)-k c^{2}$

According to the Equation 5, under the same condition, the slower the curing reaction rate of propellant is, the greater the diffusion coefficient $\mathrm{D}$ of the curing agent will be, namely the migration loss of curing agent is higher. Due to the use of IPDI curing agent of HTPB propellant cured at a low speed (the time to reach vulcanization point at $60{ }^{\circ} \mathrm{C}$ is 8 days), in 
the early curing, the migration of free IPDI curing agent in the propellant in the interfacial region can lead to further weakening of the interface properties of propellant. The greater the amount of migration is, the weaker the mechanical properties of the interface propellant will be. Compared with EPDM, the diffusion coefficient of IPDI in the NBR is greater, which leads to the weakening the mechanical properties of the interface propellant by the NBR insulation layer.

\section{Effect of thickness of insulation layer}

Because the weakening effect of NBR insulation layer on interface property is more obvious and remarkable than EPDM insulation layer, the NBR insulation layer was chosen to study the effect of the thickness of the insulation layer on interface bonding property (Table 3 ). To eliminate the influence of water, the specimen was pre-baked at $80^{\circ} \mathrm{C}$ for $2 \mathrm{~h}$. As seen in Table 3 , the thickness of NBR insulation layer has a remarkable effect on the interfacial bonding property of steel/insulation layer/liner/propellant, to be more specific, the bonding strength decreased with the increasing of the thickness of NBR insulation layer.

Figure 6 depicts that the weight loss rate of NBR insulation varies with thickness changing when heated up to $80{ }^{\circ} \mathrm{C}$. Obviously, under the same condition with the increase of the thickness of NBR insulation, the loss rate decreased, indicating that the residual water comparably in thick insulation is higher under the same heating condition. In addition, as the thickness of the insulating layer of NBR increases, the migration loss of IPDI curing agent in propellant was enhanced. The interaction of migration of water and curing agent intensified the weakening effect of the insulating layer at the interfacial with the increasing of the thickness.

Table 3. The effect of thickness of insulation layer on bonding property

\begin{tabular}{cccc} 
Sample No. & Thickess $(\mathrm{mm})$ & $\sigma_{\text {bond }}(\mathrm{Mpa})$ & Failure mode \\
7 & 2 & 0.96 & \\
& 7 & 0.77 & Cohesive failure of propellant \\
8 & 2 & 1.07 & \\
& 10 & 0.90 & \\
\hline
\end{tabular}

Figure 6. Weight loss rate of NBR insulation layer vs time at $80{ }^{\circ} \mathrm{C}$

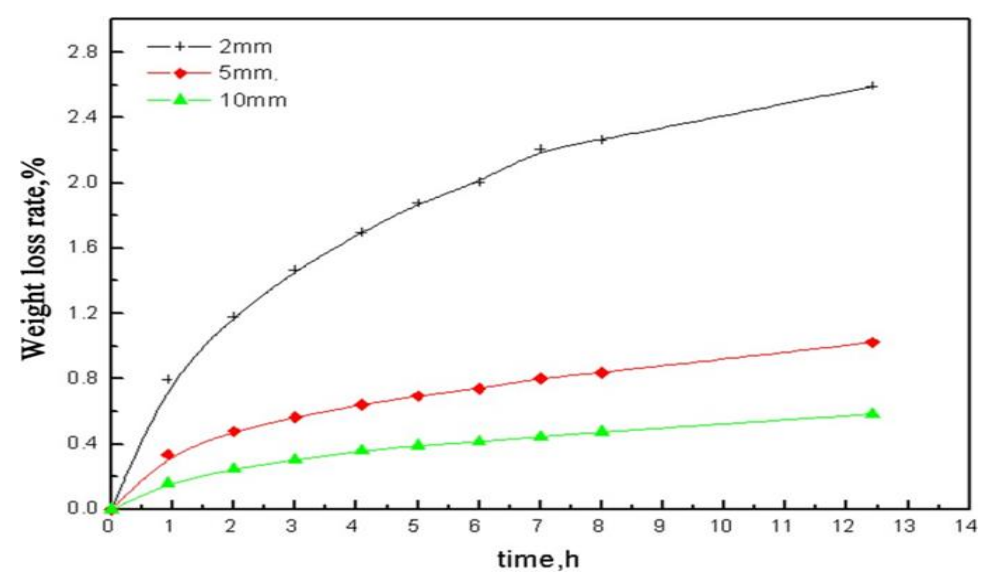


Table 4. The effect of water removal condition on bonding property

\begin{tabular}{cccc} 
Sample No. & Water removal condition & $\sigma_{\text {bond }}(\mathrm{Mpa})$ & Failure mode \\
9 & $80^{\circ} \mathrm{C} \times 1 \mathrm{~h}$ & 0.95 & \\
9 & $80^{\circ} \mathrm{C} \times 3 \mathrm{~h}$ & 1.07 & \\
& $80^{\circ} \mathrm{C} \times 12 \mathrm{~h}$ & 1.24 & Cohesive failure of propellant \\
\multirow{2}{*}{10} & $90^{\circ} \mathrm{C} \times 1 \mathrm{~h}$ & 1.01 & \\
\multirow{2}{*}{11} & $90^{\circ} \mathrm{C} \times 3 \mathrm{~h}$ & 1.12 & \\
\hline
\end{tabular}

\section{Effect of water removal condition}

During the curing of propellant, the small molecules containing active hydrogen in the insulation layer migrate to the heat-insulation layer/liner/propellant interfacial region as the concentration difference may cause the extra consumption of the curing agent in the interfacial propellant and liner. Thus, the migration process may decrease the interfacial propellant strength and bonding strength of liner/propellant interface. The active small molecules such as water molecules in the insulation layer can be driven out by heating to reduce its adverse influence. Therefore, increasing the heating temperature or prolonging the heating time is beneficial to reduce the influence of the active small molecules in the insulation layer on the interfacial bonding property as shown in Table 4.

\section{Conclusions}

This work aims at studying the bonding property between rocket propellant and the thermal insulation layer and factors affecting the performance of the insulation layer in a typical solid rocket motor. Samples characterization was performed using universal material experiment machine (INSTRON 4301) for tensile strength test and bonding evaluation.

1) Both the NBR insulation layer and the EPDM insulation layer have weakened the effect on the interfacial bonding property of the HTPB/IPDI propellant, and the influence of the NBR insulation layer is greater.

2) The small molecules containing active proton such as water in the heat-insulation layer migrate to the liner/propellant interface and the curing agent in the interface propellant migrates to the heatinsulation layer, which consumes the curing agent near the liner/propellant interface, resulting in the decrease of the interfacial bonding property. As the thickness of the heat-insulation layer enhanced, the weakening of the interfacial bonding property became more significant.

3) Drying the insulation layer before spraying or brushing the liner can reduce the negative influence of the heat-insulation layer on the bonding property at the interface.

\section{Acknowledgement}

Great thanks to Allah, my wife and my family who helped me a lot to finish this study. Best regards to all Cairo University staff.

\section{Disclosure statement}

No potential conflict of interest was reported by the authors.

\section{ORCID}

Mahmoud E. Awad (D): 0000-0003-2861-3813 


\section{References}

[1] Q.C. Zhou, J.S. Xu, X. Chen, C.S. Zhou, J. Adhes., 2015, 92, 402-428.

[2] T.V. Chelaru, F. Mingireanu, Acta Astronautica, 2011, 68, 1891-1902.

[3] M.E. Mohamed, S. El-Marsafy, S. Hasanin, T.Z. Wafy, Int. Conference Aerospace Sci. Aviat. Technol., 2017, 17, 1-11.

[4] T. Sojourner, D.E. Richardson, B.D. Allen, S. Hyde, S. McHenry, B. Goldberg, D. Devries, M. Ewing, Solid Rocket Motor Reliability and Historical Failure Modes Review, 51 st AIAA/SAE/ASEE Joint Propulsion Conference, 2015, p. 3873.

[5] E. Landsem, T.L. Jensen, F.K. Hansen, E. Unneberg, T.E. Kristensen, Propell. Exp. Pyrotechnics, 2012, 37, 581-591.

[6] S.B. Navale, S. Sriraman, V.S. Wani, M.V. Manohar, S.D. Kakade, Def. Sci. J., 2004, 54, 353-359.

[7] M. Natali, M. Rallini, D. Puglia, J. Kenny, L.
Torre, Polym. Degradat. Stab., 2013, 98, 2131-2139.

[8] H. Noorizadeh, A. Farmany, Adv. J. Chem. Section A, 2019, 2, 128-135.

[9] M. Mohamed, S. El-Marsafy, S. Hasanin, T. Wafy, J. Engin. Sci. Military Technol., 2017, 17, 1-11.

[10] L. Guo, W. Song, M. Hu, C. Xie, X. Chen, Appl. Surface Sci., 2008, 254, 2413-2417.

[11] Standard Test Methods for Vulcanized Rubber and Thermoplastic ElastomersTension, ASTM International, West Conshohocken, PA, 2016.

[12] H. Zhang, D.R. Dunphy, X. Jiang, H. Meng, B. Sun, D. Tarn, M. Xue, X. Wang, S. Lin, Z. Ji, R. Li, F.L. Garcia, J. Yang, M.L. Kirk, T. Xia, J.I. Zink, A. Nel, C.J. Brinker, J. Am. Chem. Soc., 2012, 134, 15790-15804.

[13] V.M. Litvinov, R.A. Orza, M. Klüppel, M. Van Duin, P.C.M.M. Magusin, Macromolecules, 2011, 44, 4887-4900.

How to cite this manuscript: Mahmoud E. Awad*, Mohamed Nasser, Effect of Insulation Layer Composite and Water Adsorption on Bonding Performance in Heat Barriers, Adv. J. Chem. A, 2020, 3(3), 370-377. 